\title{
Thermal Power Plant Steam Turbine Output Operational Characteristics Change Probabilistic Model Driven by the Second Derivation Control Actions
}

\author{
Sultanov Makhsud Mansurovich, Trukhanov Vladimir Mikhailovich, Gorban Yuliya Anatolyevna \\ Department of Heat Engineering, Volzhsky Branch of Moscow Power Engineering Institute, Volzhsky, Russia \\ Email address: \\ sultanov_mm@mail.ru (S. M. Mansurovich), trukhanov1939@mail.ru (T. V. Mikhailovich), yuliya.bk.ru@mail.ru (G. Y. Anatolyevna) \\ To cite this article: \\ Sultanov Makhsud Mansurovich, Trukhanov Vladimir Mikhailovich, Gorban Yuliya Anatolyevna. Thermal Power Plant Steam Turbine \\ Output Operational Characteristics Change Probabilistic Model Driven by the Second Derivation Control Actions. American Journal of \\ Electrical Power and Energy Systems. Vol. 8, No. 6, 2019, pp. 152-157. doi: 10.11648/j.epes.20190806.12
}

Received: August 1, 2019; Accepted: October 29, 2019; Published: November 25, 2019

\begin{abstract}
The subject of the research is thermal station power equipment, in particular steam turbines and steam turbine plant support equipment. In the modern context, when working lifespan of the power equipment outreached the limit, thus the goal is to assure it performance and availability for producing enough energy and heat. To reach the goal it's necessary to design and implement the probabilistic models and techniques for power equipment reliability under present day conditions. The probabilistic second derivative output parameters change model of power equipment is first developed by the authors and is the scientific novelty of the research. In the paper the assumptions and suppostitions on which the model is based are described. The practical implication of the model consists of capability of rational maintenance and repair operation term estimation of thermal power plant steam turbines. The model is based on the mathematical statistics methods, probability theory and matrix calculus. The probabilistic model allows forecasting the output characteristics change in time and control actions explicitly. The example of output characteristics change for long term utilization is given. During the research the statistical power equipment elements failure and error material has been acquired and presented in relative failure and error share diagram. The internal and external technical and operational factors influencing the failure statistics are determined. For quantitive reliability estimation of power equipment the set of primary indices, influencing turbine performance and reliability, is presented.
\end{abstract}

Keywords: Reliability Indices, Probabilistic Model, Control Actions, Turbine, Output Characteristics, Control Parameters

\section{Introduction}

In the modern context, when working lifespan of the power equipment outreached the limit, thus the goal is to assure it performance and availability for producing enough energy and heat. Operational reliability of thermal power plant equipment and its components is a current problem, for statuory service life of most of equipment is expired [1, 2]. Under study of domestic and foreign research works no similar control action probabilistic model has been found.

\section{Basic Indexes and Formulas, Impacting on Turbine Reliability}

To increase the power equipment lifetime the tasks [3] of data obtain and long term steam turbine reliability statistical information processing is set. Statistical data analysis should reveal the reasons of component, details and mechanisms failures, which affect equipment reliability directly. To support power and heat producing reliability by combined heat and power plant (CHP) the reasonable period of complete thermal power plant turbine repairs and obsolete equipment upgrade is to be defined.

The presented quantitive indexes allow equipment reliability estimation and forecasting by the statistical data and determine whether equipment repair is worth [5]. The statistical turbine failure data has been obtained from more than $800100-800 \mathrm{MW}$ steam turbine plants of various type and developer for 15 years of operation (table 1). Let's consider the most common failure causes. 
Table 1. Types and count of analyzed equipment.

\begin{tabular}{llll}
\hline Turbine type & Count & Turbine type & Count \\
\hline K-800-240 LMZ & 19 & K-300-240 KhTZ & 76 \\
K-500-240 LMZ & 6 & K- 150-130 KhTZ & 84 \\
K-300-240LMZ & 89 & T-250/300-240 TMZ & 29 \\
K-100-90 LMZ & 95 & T-175-130 TMZ & 15 \\
T-180/210-130 LMZ & 17 & K- 100-130 TMZ & 190 \\
K-500-240 KhTZ & 10 & PT-135-130 TMZ & 31 \\
\hline
\end{tabular}

In the Figure 1 the turbine type-averaged equipment failure distribution is presented $[6,7]$. The most number of failures are control system and bearing ones.

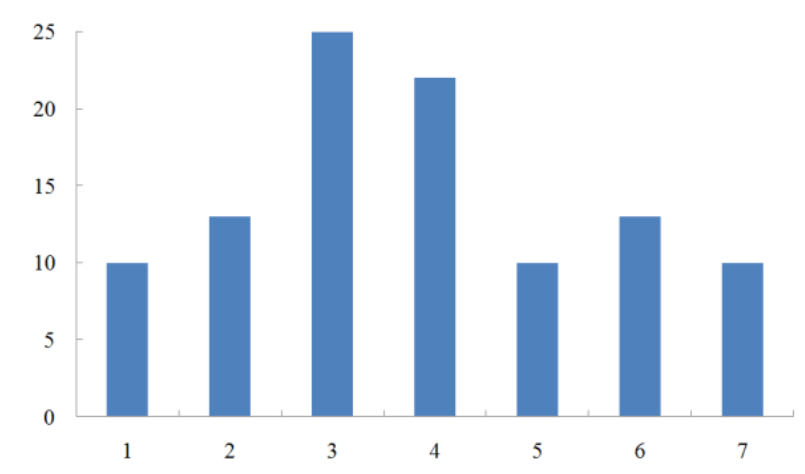

Figure 1. The turbine failure distribution by causes: 1 -flow range damage; 2 - steam distribution system damage; 3 - control system damage; 4 bearing damage; 5 - oil system damage; 6 - piping and valve damage; 7 elevated vibration.

Let us conduct an analysis of turbine failure distribution quantative meaning [4]. Most of flow range damages fall on moving blades [8]. Most moving blade damages are because of blade separation, vibration behavior change and moving blade failure due to its zero strength margin and metal fatigue capability.

Bearing reliability decreases due to its both internal and external technical and operational factors, which are babbitdisintegration, lube oil supply penalty, emergency turbine vibration condition, turbine axial shift. Bearing and rotor component damage often leads to unplanned turbine shutdown.

Turbine axial shift often appers because of abnormal load increasing and decreasing rate and utilizing steam turbines with excessive scale buildup and under limit turbine stage pressure change at points of measurements.

As part of scheduled repairs fault detection helps find rotor shaft and moving blade damages.

The most frequent defects are main oil pump oil system component, such as oil pipe damage.

The analysis of the thermal power plant turbine failures shows that different turbine component failure causes give mixed response to turbine output characteristics, such as unplanned repair time, repair personnel, repair cost, power and heat output, power and heat sale incomes etc. [9].

Qualitative analysis can represent relative fraction of turbine component failure effect on turbine output characteristics overall.

According to the statistical data it's possible to work out output characteristics improvement measures. It's so called passive output characteristics control model. In order to control output characteristics explicitly the probabilistic model based on the following assumptions is suggested [5]:

(1) turbine is operated complexly considering different load, temperature and vibration and etc. conditions;

(2) in case of failure and its cause detection the equipment should be maintained;

(3) the damage control should be complex, i:. it should concern not only the damaged component, but others, which are functionally related to the power and heat generation schedule.

It should be mentioned, that the component technological or operational parameter variation are correlation dependent on failed component and have a direct impact on the component output characteristics thus indirect impact on the turbine one.

\section{A Probabilistic Model of Control Actions}

The correlation dependence between parameters of failed component and functionally related ones can be found with the classical mathematical statistics approaches and correlation coefficients $b_{i j}$, which then are inserted in the measure regression equation $(1)[10,11]$ :

$$
\mathrm{y}_{\mathrm{i}}(\mathrm{t})=\mathrm{b}_{\mathrm{i} 1} \mathrm{u}_{1}(\mathrm{t})+\mathrm{b}_{\mathrm{i} 2} \mathrm{u}_{2}(\mathrm{t})+\ldots+\mathrm{b}_{\mathrm{im}} \mathrm{u}_{\mathrm{m}}(\mathrm{t})
$$

where $y_{i}(t)$ - turbine or component output characteristics at the moment of $i$-th measure.

Let us set $b_{i j}=b_{i j k}$, where $b_{i j k}$ is correlation coefficient between $\mathrm{j}$-th and $\mathrm{k}$-th components (parameters) at the moment of $i$-th measure. The correlation coefficients are calculated by ratio (2) - (4):

$$
\begin{gathered}
b_{i j k}=\frac{M_{i j k}}{\sigma_{i j} \sigma_{i k}} ; \\
M_{i j k}=\frac{\sum_{i=1}^{n}\left(u_{i j}-\bar{u}_{j}\right)\left(u_{i k}-\bar{u}_{k}\right)}{n-1} ; \\
\sigma_{i j}=\sqrt{\frac{\sum_{i=1}^{n}\left(u_{i j}-\bar{u}_{j}\right)^{2}}{n-1}} ; \sigma_{i k}=\sqrt{\frac{\sum_{i=1}^{n}\left(u_{i k}-\bar{u}_{k}\right)^{2}}{n-1}},
\end{gathered}
$$

where $\mathrm{M}_{\mathrm{ijk}}$ - $\mathrm{j}$-th and $\mathrm{k}$-th components covariance coefficient; $\sigma_{i j}$ and $\sigma_{i k}-$ mean square deviation of $j$-th and $k$-th components respectively; $\overline{\mathrm{u}}_{\mathrm{j}}$ and $\overline{\mathrm{u}}_{\mathrm{k}}$ - average $\mathrm{j}$-th and $\mathrm{k}$-th control parameter values; $\mathrm{i}=1,2, \ldots, \mathrm{n} ; \mathrm{j}$ and $\mathrm{k}=1,2, \ldots$, $\mathrm{m}$.

Control parameters $\mathrm{u}_{\mathrm{ij}}$ can be represented as control functions, derived control function, second derivative of control function etc. The turbine operation statistical data can show technological, operational and other parameters functional dependences and correlations and their impact on 
turbine and its component output characteristics $[12,13]$.

The assumptions help using matrix calculus mathematical apparatus in the probabilistic model development. In this case in generation of the measure equation as the equation parameter change influence coefficient $\mathrm{u}_{\mathrm{ij}}$ the statistical data correlation coefficients $b_{i j}$ are used. Matrix calculus could be avoided if each control $u_{i}$ has impacted only on one characteristic $\mathrm{y}_{\mathrm{i}}$. In that case the control matrix is diagonal and the matrix approach can't show extra information as compared with scalar models, which are one for each characteristic.

Taking into account the thermal plant steam turbine measure features, let us consider a task of control action determination in an explicit analytical form. To solve the task the following suppositions are made. When developing a probabilistic model the system model is undefined and the necessary control actions are found by setting the system evolving dynamics and control law [14]. Considering the specifics of the task the new class of desired control laws and assumption that the desired system evolving dynamics is exponential (continuous) are taking into an account, what helps avoid non-linear equations.

With that approach to the task it's possible to get a system of linear equations, providing explicit control actions determination. The probabilistic model can be represented as a system of input, output and state on Figure 2.

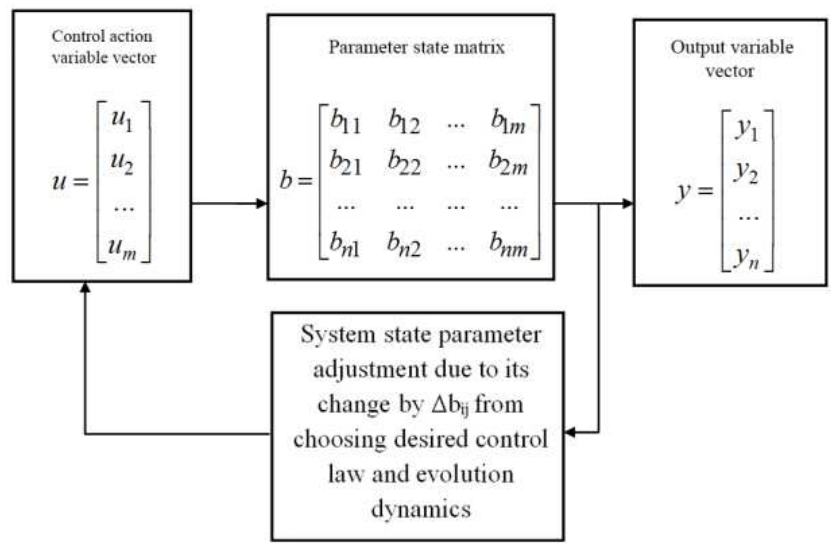

Figure 2. Control action probabilistic model.

The system input is a primary equipment and its component (turbine, rotor, bearing, pipework, oil system etc.) failure quota change control action vector expressed as relative fraction. The system state matrix is a set of design, technological and operational parameters. The output characteristics can be unplanned repairs coefficient, power or heat generation, failure interval, probability of failure-free operation etc.

Let us consider a case, when the output characteristic is failure interval change expressed as (5):

$$
y_{i}(t)=T d_{i}(t)-T_{i}(t)
$$

where $\operatorname{Td}_{i}(t)$ - desired failure interval of $i$-th component by $\mathrm{j}$-th parameter and is a scalar; $\operatorname{Ti}(\mathrm{t})$ - current failure interval of $i$-th component at the moment $t$.

The process is based on increasing $\mathrm{T}_{\mathrm{i}}(\mathrm{t})$, and therefore on the function (5) value nullification. The control action determination mathematical algorithm is described in paper [5] in details.

Any adjustment is made only when the certain number of the factors, which necessitate it. In numerical terms it's expressed the following way. If the fabrication input characteristic is a central moment, expressed in function of time $y(t)=T d(t)-T(t)$ for improvement, then control action $u(t)$ should be proportional to the time integral at $[0$, t0]. These concerns await choosing the following form of desired control law (6):

$$
B \cdot u(t)=\int_{0}^{t} y(\tau) d \tau
$$

where B - a experience-based data constant; $\tau$ - variable of integration.

Equipotential format (7):

$$
\mathrm{B} \frac{\mathrm{dU}(\mathrm{t})}{\mathrm{dt}}=\mathrm{y}(\mathrm{t})
$$

where $u(t=0)=0$.

Therefore, if control parameters $u_{j}$ and output characteristics increase and $y(t)=\exp (-t / T)$ then in a generic form the control action vector at pre-assigned value of operational time $\mathrm{T}$ can be found by the formula (8) [5]:

$$
u_{j}(t)=u_{j}^{0}+T\left(1-\exp \left(-\frac{t}{T}\right)\right) B^{+} y d \text {, where } B+-B
$$

pseudo inversed matrix; $u_{j}^{0}-$ initial value of control parameter.

The expanded form of the vector (9):

$$
\begin{aligned}
& {\left[\begin{array}{c}
\mathrm{u}_{1}(\mathrm{t}) \\
\mathrm{u}_{2}(\mathrm{t}) \\
\ldots \\
\mathrm{u}_{\mathrm{m}}(\mathrm{t})
\end{array}\right]=\left[\begin{array}{c}
\mathrm{u}_{1}^{0}(\mathrm{t}) \\
\mathrm{u}_{2}^{0}(\mathrm{t}) \\
\ldots \\
\mathrm{u}_{\mathrm{m}}^{0}(\mathrm{t})
\end{array}\right]+\mathrm{T}(1-\exp (-\mathrm{t} / \mathrm{T})) .} \\
& {\left[\begin{array}{cccc}
\mathrm{b}_{11} & \mathrm{~b}_{12} & \ldots & \mathrm{b}_{1 \mathrm{~m}} \\
\mathrm{~b}_{21} & \mathrm{~b}_{22} & \ldots & \mathrm{b}_{2 \mathrm{~m}} \\
\ldots & \ldots & \ldots & \ldots \\
\mathrm{b}_{\mathrm{n} 1} & \mathrm{~b}_{\mathrm{n} 2} & \ldots & \mathrm{b}_{\mathrm{nm}}
\end{array}\right]^{+}\left[\begin{array}{c}
\mathrm{yd}_{1} \\
\mathrm{yd}_{2} \\
\ldots \\
\mathrm{yd}_{\mathrm{n}}
\end{array}\right] .}
\end{aligned}
$$

If the control parameter $u_{j}$ decreases relatively to the initial value $u_{j}^{0}$, but output characteristics $y_{j}$ increase, then (10):

$$
\mathrm{u}_{\mathrm{j}}(\mathrm{t})=\mathrm{u}_{\mathrm{j}}^{0}-\mathrm{T}(1-\exp (-\mathrm{t} / T)) \mathrm{B}^{+} \mathrm{yd}
$$

Let us consider a case, when an equipment or its units are being repaired and restored within a shorter period of time, i.e. the output characteristic $y(t)$ changes proportionaly to the $\mathrm{j}$-th control parameter speed rate and is defined in the 
regression form by ratio (11) [5]:

$$
\mathrm{y}(\mathrm{t})=\mathrm{Bü}(\mathrm{t})
$$

or in the expanded form (12):

$$
y_{i j}(t)=b_{i 1} \ddot{u}_{1}(t)+b_{i 2} \ddot{u}_{2}(t)+\ldots+b_{i m} \ddot{u}_{m}(t),(i=\overline{1, n}) ;(j=\overline{1, m}) \text {. }
$$

Then the solution of the task for the desired control law, expressed by formula (8), is (13):

$$
u(t)=B^{+} y d(t)
$$

At output characteristic exponential distribution law (14):

$$
\ddot{u}(t)=B^{+} \exp (-D t) y d(t) \text {. }
$$

Integrating formula (14) results in equation (15):

$$
\dot{u}(t)=u_{v}^{0}+B^{+} \int_{0}^{T} \exp (-D t) y d(t) d t
$$

where $u_{v}^{0}-$ initial value of control parameter change rate by time (16):

$$
\begin{aligned}
& \text { (16) } u_{\mathrm{vj}}^{0}=\frac{\mathrm{u}_{\mathrm{j}}-\mathrm{u}_{\mathrm{j}-1}}{\mathrm{u}_{\mathrm{j}-1}} \\
& \int_{0}^{\mathrm{T}} \exp (-\mathrm{Dt}) \mathrm{yd}(\mathrm{t}) \mathrm{dt}=\frac{1}{\mathrm{D}}(1-\exp (-\mathrm{Dt})) \mathrm{yd}(\mathrm{t}) .
\end{aligned}
$$

Integral of formula (15):

$$
u(t)=u^{0}+u_{v}^{0} t+B^{+} \int_{0}^{T} \frac{1}{D}(1-\exp (-D t)) y d(t) d t .
$$

Integrating (18) results in equation (19):

$u(t)=u^{0}+u_{v}^{0} t+B^{+} T[1-T(1-\exp (-t / T))] y d(t)$

If control parameters $u_{j}$ decrease, but output characteristics $\mathrm{y}_{\mathrm{j}}$ increase, then (20):

$$
\mathrm{u}(\mathrm{t})=\mathrm{u}^{0}-\mathrm{u}_{\mathrm{v}}^{0} \mathrm{t}-\mathrm{B}^{+} \mathrm{T}[1-\mathrm{T}(1-\exp (-\mathrm{t} / \mathrm{T}))] \mathrm{yd}(\mathrm{t}) .
$$

The described equipment life cycle process control probabilistic model can be used when constraining both output characteristics and control parameters.

\section{Example of Assessment of Control Actions}

Let us consider the case of control action evaluation by the statistical data from paper [3].

During the operation of PT-65-130, P-50-130, T-50-130, T-100-130 and PT-135-130 turbine the component failures, resulting in turbine reliability decreasing, were recorded. The turbine operation results as respective parameter change values are represented in table 2 .

Table 2. The turbine failure flow and unplanned repairs parameters statistical data according to power and heat generation by years of operation.

\begin{tabular}{lllll}
\hline $\mathbf{u}_{\mathbf{1}}, \mathbf{G c a l}$ & $\mathbf{u}_{\mathbf{2}}, \mathbf{M W h}$ & $\mathbf{y}_{\mathbf{1}} \cdot \mathbf{1 0}^{\mathbf{- 3}}, \mathbf{h}^{\mathbf{- 1}}$ & $\mathbf{y}_{\mathbf{2}}, \mathbf{\%}$ & $\mathbf{t}$, year \\
\hline 7 & 8 & 0.05 & 0.33 & 1 \\
6.9 & 7.8 & 0.05 & 0.33 & 2 \\
6.8 & 7.5 & 0.05 & 0.33 & 3 \\
6.5 & 7 & 0.07 & 0.49 & 4 \\
5 & 6 & 0.12 & 0.82 & 5 \\
\hline
\end{tabular}

The statistical operational data analysis (table 2) shows that with failure rate $\lambda$ and forced repairs factor $\mathrm{K}_{\mathrm{fr}}$ increase heat $\mathrm{u} 1$ and power $\mathrm{u} 2$ generation decreases as confirmed by the actual power equipment operating mode.

The optimal control parameters as heat and power generation change need to be defined, which confirm evidence for desired output values of yd: failure rate $\mathrm{y} 1, \mathrm{~h}-1$; forced repairs factor y2,\% during $\mathrm{T} 0$ year service.

The rational control parameters calculated by first and second derivative of functions (10) and (20) are represented in table 2 and Figure 3.

The solution algorithm:

1. Let us set the desired output characteristic evolution dynamics, expressed in exponential form (21)

$$
y(t)=\exp (-\lambda t) \cdot y d=\exp (-\lambda t) \cdot y d
$$

2. Let us choose the desired control law proportional to the output characteristic change integral (22):

$$
B\left[u(t)-u^{0}\right]=\int_{0}^{T} \exp (-\lambda t) \cdot y^{0} d t .
$$

3. Let us refer the statistical turbine operation data results (for instance, ones from table 1).

4. According to the desired control law the source data table is transformed to the parent matrices. In this case (23) and (24):

$$
\begin{gathered}
y_{j}\left(t_{i}\right)=\frac{y_{1 j}+y_{2 j}}{2} \Delta t_{1}+\frac{y_{2 j}+y_{3 j}}{2} \Delta t_{2}+\cdots+\frac{y_{i-j}+y_{i j}}{2} \Delta t_{i}, \\
u=\left[u(t)-u^{0}\right]
\end{gathered}
$$

where $\mathrm{j}=\overline{1, \mathrm{~m}}=1,2 ; \mathrm{i}=\overline{1, \mathrm{n}}=1,2,3,4,5$.

The transform result is $m \times(n-1)$ matrices $u$ and $y(t)(25)$ :

$$
\mathrm{u}=\left[\begin{array}{ll}
\mathrm{u}_{11} & \mathrm{u}_{12} \\
\mathrm{u}_{21} & \mathrm{u}_{22} \\
\mathrm{u}_{31} & \mathrm{u}_{32} \\
\mathrm{u}_{41} & \mathrm{u}_{42}
\end{array}\right], \quad \mathrm{y}(\mathrm{t})=\left[\begin{array}{ll}
\mathrm{y}_{11} & \mathrm{y}_{12} \\
\mathrm{y}_{21} & \mathrm{y}_{22} \\
\mathrm{y}_{31} & \mathrm{y}_{32} \\
\mathrm{y}_{41} & \mathrm{y}_{42}
\end{array}\right] .
$$

5. Then matrix $u$ is transposed.

6. Let us find transposed pseudo inverse matrix $\left[\mathrm{y}^{+}\right]^{\mathrm{T}}$ for 
parent matrix $y(t)$ with MATLAB built-in functions:

$$
\left[y^{+}\right]^{\mathrm{T}}=\left[\begin{array}{cc}
127.00 & -18.81 \\
253.99 & -37.62 \\
124.30 & -18.25 \\
-198.58 & 29.89
\end{array}\right]
$$

7. The pseudo inverse matrix $\hat{\mathrm{B}}^{+}=\mathrm{u}^{\mathrm{T}}\left[\mathrm{y}^{+}\right]^{\mathrm{T}}$ evaluation is calculated with least square method:

$$
\hat{\mathrm{B}}^{+}=\left[\begin{array}{ll}
271.50 & -41.26 \\
120.46 & -18.96
\end{array}\right] .
$$

8. Let us define the control actions for the desired output characteristic evolution dynamics and control law. We set the operational period $\mathrm{T}_{0}=5$ and $\mathrm{T}=\mathrm{T}_{0} / 5$. For the control parameters $u_{j}$ decrease, but the output characteristics $\mathrm{y}_{\mathrm{j}}$ increase, then (26):

$$
\begin{aligned}
& u_{j}(t)=u_{j}^{0}-u_{v j}^{0} t-T_{0} / 5\left(1-\exp \left(-5 t / T_{0}\right)\right) \hat{B}^{+} y d= \\
& =u_{j}^{0}-u_{v j}^{0} t+(1-\exp (-t)) \hat{B}^{+} y d .
\end{aligned}
$$

The expanded form of the vector (27):

$$
\begin{aligned}
& {\left[\begin{array}{c}
\mathrm{u}_{1}(\mathrm{t}) \\
\mathrm{u}_{2}(\mathrm{t}) \\
\ldots \\
\mathrm{u}_{\mathrm{m}}(\mathrm{t})
\end{array}\right]=\left[\begin{array}{c}
\mathrm{u}_{1}^{0}(\mathrm{t}) \\
\mathrm{u}_{2}^{0}(\mathrm{t}) \\
\ldots \\
\mathrm{u}_{\mathrm{m}}^{0}(\mathrm{t})
\end{array}\right]-\left[\begin{array}{c}
\mathrm{u}_{\mathrm{v} 1}^{0}(\mathrm{t}) \\
\mathrm{u}_{\mathrm{v} 2}^{0}(\mathrm{t}) \\
\ldots \\
\mathrm{u}_{\mathrm{vm}}^{0}(\mathrm{t})
\end{array}\right] \cdot \mathrm{t}-} \\
& -(1-\exp (-\mathrm{t}))\left[\begin{array}{cccc}
\mathrm{b}_{11} & \mathrm{~b}_{12} & \ldots & \mathrm{b}_{1 \mathrm{~m}} \\
\mathrm{~b}_{21} & \mathrm{~b}_{22} & \ldots & \mathrm{b}_{2 \mathrm{~m}} \\
\ldots & \ldots & \ldots & \ldots \\
\mathrm{b}_{\mathrm{n} 1} & \mathrm{~b}_{\mathrm{n} 2} & \ldots & \mathrm{b}_{\mathrm{nm}}
\end{array}\right]^{+}\left[\begin{array}{c}
\mathrm{yd}_{1} \\
\mathrm{yd}_{2} \\
\ldots \\
\mathrm{yd}_{\mathrm{n}}
\end{array}\right] .
\end{aligned}
$$

After setting the input data $u_{j}^{0}, \hat{B}^{+}$, yd and $t=1,2,3,4,5$, we can find the corresponding control parameter values for data from table 3 .

$$
\begin{aligned}
& {\left[\begin{array}{l}
\mathrm{u}_{1}(\mathrm{t}) \\
\mathrm{u}_{2}(\mathrm{t})
\end{array}\right]=\left[\begin{array}{l}
7 \\
8
\end{array}\right]-\left[\begin{array}{lllll}
0 & -0.03 & -0.04 & -0.18 & -1.15 \\
0 & -0.05 & -0.12 & -0.27 & -0.71
\end{array}\right]-} \\
& -(0.63,0.86,0.95,0.98,0.99)\left[\begin{array}{ll}
271.50 & -41.26 \\
120.46 & -18.96
\end{array}\right]\left[\begin{array}{l}
0.12 \\
0.82
\end{array}\right] \text {. }
\end{aligned}
$$

Table 3. The calculated first and second derivation control parameter values.

\begin{tabular}{llllll}
\hline \multirow{2}{*}{ Control parameter } & \multicolumn{7}{c}{ Operation year } & & & \\
\cline { 2 - 6 } & $\mathbf{1}$ & $\mathbf{2}$ & $\mathbf{3}$ & $\mathbf{4}$ & $\mathbf{5}$ \\
\hline $\begin{array}{l}\text { The first derivation } \\
\text { u1(t) - heat generation }\end{array}$ & 7.79 & 8.08 & 8.19 & 8.23 & 8.24 \\
$\begin{array}{l}\text { u2(t) - electric power } \\
\text { generation }\end{array}$ & 8.69 & 8.95 & 9.04 & 9.07 & 9.09 \\
$\begin{array}{l}\text { The second derivation } \\
\text { u1(t) - heat generation }\end{array}$ & 7.79 & 8.11 & 8.23 & 8.40 & 9.39 \\
$\begin{array}{l}\text { u2(t) - electric power } \\
\text { generation }\end{array}$ & 8.69 & 9.00 & 9.16 & 9.34 & 9.80 \\
\hline
\end{tabular}

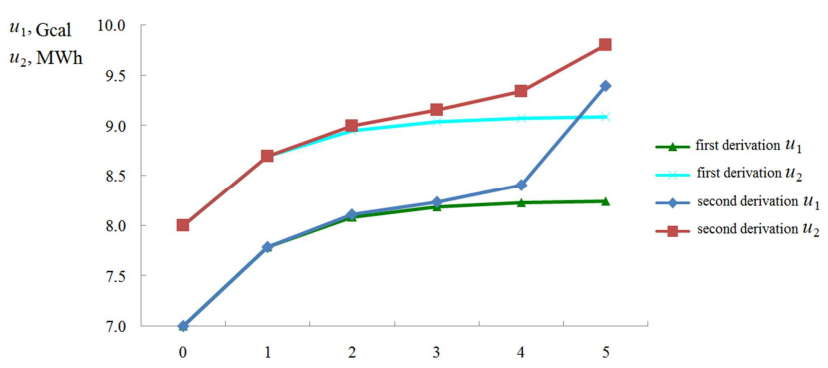

Figure 3. Control parameter - operation year relationship.

It follows from the analysis of table 3 and Figure 3, that with operational period increase it's recommended to work out the repairs (operating or complete) measures yearly adjusting heat and power generation to the desired values, for power equipment realibility degrades each year.

The qualitative analysis of table 2 shows that second derivation control is more advantageous, because it allows reaching better control parameter values.

\section{Conclusions}

1. In the paper the quantitive and qualitative analysis of heat and power facility steam turbine component and unit performance is conducted according to the turbine statistical data; the analysis indicates the liable to failure turbine components.

2. The developed probabilistic thermal power plant turbine output characteristics change model upon reliability indexes illustrated by the example of heat and power generation is matched by the turbine output characteristics change with operational period.

3. The developed second derivation control parameter change probabilistic model is more advantageous, for it provides generation of desired amount of heat and power process acceleration by the repairs and maintenance speedup measures saving the proper operational year-wise reliability.

\section{Acknowledgements}

The research is executed within the state task No. 13.9602.2017/BCh on a subject 1041170 .

\section{References}

[1] Regulation of Rosseti OJSC on a unified technical policy in the electric grid complex. M., 2013.

[2] Sultanov M. M. Anohina E. P. Analysis of the energy efficiency of modern generating systems // The Twenty-First Inter-University Scientific and Practical Conference of Young Scientists and Students. Volzhsky, May 25 - 29, 2015: Abstracts. Volzhsky: Branch of FSBEI HE "NRU" MPEI "in Volzhsky, 2015. P. 6-8.

[3] Sultanov M. M. Assessment of reliability, extension of service life and optimization of repair of thermal power plant equipment and power systems. - Volzhsky: Volzhsky branch of MPEI, 2016.-100 p. 
[4] Repair of steam turbines: a training manual / V. N. Rodin [et al.]; under the general. ed. Yu. M. Brodova, V. N. Homeland. Ekaterinburg: USTU-UPI, 2002.

[5] Truhanov V. M. Reliability in technology. M.: Edition «Spektr», 2017. $-634 \mathrm{p}$.

[6] ISO 153-34.17.440-2003. Instructions for extending the life of steam turbines beyond the park resource. M.: TISC ORGRES, 2004.

[7] Pozdyshev A. A., Rabenko V. S. About damage to steam turbines of TPPs // Vestnik IGEU. 2004. Issue. 2. pp. 19-23.

[8] Failure analysis to blades of steam turbines at normal conditions of operations and resonance / A. L. Tejeda [et al.] // Advanced Materials Research. 2014. Vols. 891-892. P. 54-59.

[9] SultanovM. M., TruhanovV. M. Mathematical model of change of output operational characteristics of steam turbines of TPP //The reliability and security of energy. -2017 . - T. 10, №1. - pp. 42-47.

[10] Truhanov V. M., Sultanov M. M., Kukhtik M. P., GorbanYu. A. Mathematical model of predicting of failures by statistical method at testing of prototypes of heat-power equipment of power supply systems of TEHS// The reliability and security of energy. - 2018. - T. 11, № 3. - pp. 235-240.

[11] Truhanov V. M. Mathematical models of the growth of the reliability level of a technical system taking into account control actions expressed in the form of probabilities and imposed restrictions // Problems of Mechanical Engineering and Machine Reliability. - 2016. No. 4. pp. 39-43.
[12] Ventzel E. S. Probability Theory: A Textbook. M.: Higher school, 2001.

[13] Gantmakher F. R. Matrix Theory: Monograph. M.: FIZMATLIT, 2004.

[14] GartungYu. A. A study of the development of dynamical systems due to some differential programs. M.: Nauka, 1984.

[15] Sultanov M. M., Truhanov V. M., Arakelyan E. K., Kulikova M. A. Methods of achieving and ensuring a high level of reliability and safety of power equipment of TPP, HPP, NPP at all stages of the life cycle, ISSN: 2312-055X, 2018. -6-14 p.

[16] Chervonyj A. A., Luk'yashchenko V. I., Kotin L. V. Reliability of complex systems. M.: Engineering, 1972.

[17] Salomon D., Motta G. Handbook of data compression // Springer Science \& Business Media. - 2010.

[18] Mashkov A. V. Economics of combined production of heat and electricity: Tutorial. Volzhskiy: Volzhsky branch of MPEI, 2012.

[19] Sultanov M. M., Truhanov V. M. Mathematical model of changes in the output performance of steam turbines of thermal power plants // Reliability and safety of energy. - 2017. pp. 81-86.

[20] Truhanov V. N., Sultanov M. M. Estimation technique of corrective effects for forecasting of reliability of the designed and operated objects of the generating systems // Journal of Physics: Conference Series. - 2017. pp. 01-13. 